\title{
Enzyme Replacement Therapy in a Feline Model of Maroteaux-Lamy Syndrome
}

\author{
Allison C. Crawley, Doug A. Brooks, Vivienne J. Muller, Birgit A. Petersen, Elizabeth L. Isaac, Julie Bielicki, Barbara M. King, \\ Christine D. Boulter, Alison J. Moore, ${ }^{\star}$ Nick L. Fazzalari, ${ }^{*}$ Don S. Anson, Sharon Byers, and John J. Hopwood \\ Lysosomal Diseases Research Unit, Department of Chemical Pathology, Women's and Children's Hospital, North Adelaide S.A. 5006, \\ Australia; and *Institute of Medical and Veterinary Science, Frome Road, Adelaide S.A. 5000, Australia
}

\begin{abstract}
We report studies that suggest enzyme replacement therapy will result in a significant reduction in disease progression and tissue pathology in patients with Maroteaux-Lamy syndrome (Mucopolysaccharidosis type VI, MPS VI). A feline model for MPS VI was used to evaluate tissue distribution and clinical efficacy of three forms of recombinant human $\mathrm{N}$-acetylgalactosamine-4-sulfatase (rh4S, EC 3.1.6.1). Intravenously administered rh4S was rapidly cleared from circulation. The majority of rh4S was distributed to liver, but was also detected in most other tissues. Tissue half-life was $\sim 2-$ $4 \mathrm{~d}$. Three MPS VI cats given regular intravenous infusions of rh4S for up to 20 mo showed variable reduction of storage vacuoles in Kupffer cells and connective tissues, however cartilage chondrocytes remained vacuolated. Vertebral bone mineral volume was improved in two MPS VI cats in which therapy was initiated before skeletal maturity, and increased bone volume appeared to correlate with earlier age of onset of therapy. One cat showed greater mobility in response to therapy. (J. Clin. Invest. 1996. 97:1864-1873.) Key words: mucopolysaccharidosis VI • lysosomal storage diseases • genetics, medical • disease models, animal • dysostoses
\end{abstract}

\section{Introduction}

The mucopolysaccharidoses (MPS) ${ }^{1}$ are a group of devastating genetic disorders, characterized at the cellular level by the storage of mucopolysaccharides in the lysosomes of most cell types. Storage results from a deficiency of 1 of 10 lysosomal enzymes required for the lysosomal degradation of mucopolysaccharides. The MPS affect children in their first few years of life and may lead to their death usually before their

Address correspondence to J.J. Hopwood, Lysosomal Diseases Research Unit, Department of Chemical Pathology, Women's and Children's Hospital, 72 King William Road, North Adelaide, South Australia, 5006, Australia. Phone: 8-204-7293; FAX: 8-204-7100.

Received for publication 14 November 1995 and accepted in revised form 31 January 1996.

1. Abbreviations used in this paper: $\mathrm{CHO} \mathrm{rh} 4 \mathrm{~S}$, rh4S prepared from Chinese hamster ovary cell line; ERT, enzyme replacement therapy; f4S, feline 4-sulfatase; LEC rh4S, rh4S prepared from LEC-1 cell line; LEC-P rh4S, dephosphorylated LEC rh4S; LSD, lysosomal storage disorder; MPS VI, MPS type VI; MPS, mucopolysaccharidoses; MUS, 4-methylumbelliferyl sulfate; rh4S, recombinant human $N$-acetylgalactosamine-4-sulfatase; SC, subcutaneously.

J. Clin. Invest.

(C) The American Society for Clinical Investigation, Inc.

0021-9738/96/04/1864/10 \$2.00

Volume 97, Number 8, April 1996, 1864-1873 10th year (1). The MPS have an overall incidence of 1:15,000 births with individual MPS types showing variable incidence from 1:30,000 for MPS III to greater than 1:100,000 for MPS VI $(2,3)$. The MPS are a subgroup of lysosomal storage disorders (LSD) which have an overall incidence of 1:5,000 births. Clinical phenotypes observed within each MPS type vary from relatively mild to extremely severe.

Mucopolysaccharidosis type VI (MPS VI, MaroteauxLamy syndrome), first described in 1965 (4), is due to a deficiency in $\mathrm{N}$-acetylgalactosamine-4-sulfatase which results in the accumulation of dermatan sulfate within lysosomes (1). Severely affected MPS VI patients are usually diagnosed under two years of age, with clinical features that include gross abnormalities of the skeleton and heart, joint stiffness, cloudy corneas, hepatosplenomegaly, dermatan sulfaturia, and premature death usually in late childhood to early adulthood. Mildly affected MPS VI patients, with similar organ involvement, live into their forties and fifties.

For the majority of LSD, the only therapy available for patients has been bone marrow transplantation, and this has been with limited clinical and biochemical evidence of success $(5,6)$. Early attempts at enzyme replacement therapy (ERT) for LSD patients were unsuccessful because insufficient enzyme doses were administered and enzymes lacked appropriate signals for efficient endocytosis, and therefore failed to reach lysosomes of cells demonstrating pathology (7). More recently, clinical efficacy of ERT was demonstrated in the LSD Type I Gaucher disease, using glucocerebrosidase prepared from human placenta, modified to expose $\alpha$-mannosides to achieve specific and efficient uptake into macrophage-type cells via a mannoside receptor $(8,9)$. Unlike severely affected MPS I, II, and VII patients, MPS VI patients generally lack central nervous system involvement. Therefore, as administered enzyme does not need to cross the blood brain barrier, MPS VI is potentially more amenable to ERT than other MPS, and is also an excellent model to evaluate the efficacy of ERT.

MPS VI has been observed in cats $(10,11)$ and rats $(12)$. The feline model of MPS VI provides a valuable opportunity to evaluate proposed therapies since the pathology closely parallels that found in humans $(10,11)$. ERT has recently been evaluated in a murine model of MPS VII using recombinant murine $\beta$-D-glucuronidase $(13,14)$. Lysosomal storage of glycosaminoglycans was prevented or delayed in hepatocytes, Kupffer cells, spleen, heart, and kidney interstitial cells and retinal pigment epithelium, but not in corneal stroma, aortic media and chondrocytes (14). There was also decreased lysosomal storage in some central nervous system cells including neurons compared with no decrease in neuronal storage following bone marrow transplantation in young adult MPS VII mice (15). ERT in MPS I dogs reduced lysosomal storage in hepatocytes, Kupffer cells, spleen and some cells in the renal glomeruli, but no improvement in brain, heart valves, cornea, and chondrocytes was observed (16). Dogs were injected intravenously weekly for 3 mo at very low doses compared with the 
ERT trials in MPS VII mice. These studies are promising and indicate ERT will prove valuable in treatment of LSD patients.

$\mathrm{N}$-acetylgalactosamine-4-sulfatase was originally purified and characterized from human liver $(17,18)$, and subsequently full length cDNA clones isolated $(19,20)$. Stably transfected Chinese hamster ovary $(\mathrm{CHO})$ cells secrete large amounts of recombinant h4S (rh4S) (21) in cell culture. The mannose-6phosphate receptor was shown to mediate uptake of $\mathrm{CHO}$ rh4S in skin fibroblasts by inhibition studies with mannose-6phosphate (21). rh4S from a $\mathrm{CHO}$ cell derived mutant, the LEC-1 cell line, which has altered N-linked glycosylation due to a lack of $N$-acetylglucosamine-transferase (22) was equally inhibited by the same concentration of mannose-6-phosphate. However, uptake into rat alveolar macrophages was inhibited by $\sim 60 \%$ by mannan for LEC rh4S only, indicating differences in glycosylation between $\mathrm{CHO}$ and LEC rh4S (M. Fuller, unpublished observations).

We now report the tissue distribution of three forms of rh4S in normal cats, and the results of long term ERT in MPS VI cats using two of these rh4S forms.

\section{Methods}

Enzyme production and purification. A rh4S construct using the human polypeptide-chain-elongation factor-1 $\alpha$ gene promoter (23) was inserted into $\mathrm{CHO}$ and LEC-1 cells (American Type Culture Collection, Rockville, MD) to express $\mathrm{CHO}$ rh4S and LEC rh4S respectively. Culture medium from both expression cell lines was harvested and purified (21), using monoclonal antibody F58.3 (24) in place of ASB 4.1. Enzyme used for distribution studies was purified using a four column procedure, to the same degree of purification (unpublished). Enzyme, concentrated over an Amicon YM-10 membrane and sterile filtered into phosphate buffered saline (PBS) ready for injection, was assayed for activity within $24 \mathrm{~h}$ of use, using the fluorogenic substrate 4-methylumbelliferyl sulfate (18) (MUS) (Sigma Chemical Co., St. Louis, MO). The mean specific activity of $\mathrm{CHO}$ rh4S was $26,220 \pm 6,025 \mathrm{nmol} / \mathrm{min} / \mathrm{mg}(n=32)$ and for LEC rh4S was $29,930 \pm 7,250 \mathrm{nmol} / \mathrm{min} / \mathrm{mg}(n=15)$. Enzyme dose was calculated according to enzyme activity. Purified enzyme was stored at $4^{\circ} \mathrm{C}$ until use. To ensure uniformity of purified $\mathrm{rh} 4 \mathrm{~S}$, each preparation was run on SDS-PAGE under reducing conditions and, as previously shown (21), all preparations contained a mixture of $\sim 70 \%$ precursor $(66$ $\mathrm{kD})$ and $30 \%$ mature $(57,43,7$, and $8 \mathrm{kD})$ polypeptides. There were no other polypeptides observed.

A portion $(5 \mathrm{mg})$ of the purified LEC rh4S had the terminal phosphate of the carbohydrate chain removed (denoted by LEC-P) by coincubation with $11 \mathrm{mg}$ bovine intestinal alkaline phosphatase (EC 3.1.3.1, Type VII-N; Sigma Chemical Co.) in dimethylglutarate buffer at $\mathrm{pH} 6$ for $16 \mathrm{~h}$ at $37^{\circ} \mathrm{C}$. It was then run on a F58.3 monoclonal antibody column as above and dialyzed into PBS and assayed for activity ready for injection. Specific activity remained unchanged following dephosphorylation $(32,590 \mathrm{nmol} / \mathrm{min}$ per $\mathrm{mg})$.

Experimental animals. All animals used in these studies were bred in an outdoor housed colony originally established from heterozygotes obtained from M. Haskins (School of Veterinary Medicine, University of Pennsylvania, Philadelphia, PA) (11). Normal cats were identified as having peripheral leukocyte feline 4-sulfatase (f4S) levels within normal limits, while MPS VI cats had non detectable levels of $\mathrm{f} 4 \mathrm{~S}$ in peripheral leukocytes and excreted excessive amounts of urinary dermatan sulfate. $\mathrm{f} 4 \mathrm{~S}$ activities were measured using radiolabeled trisaccharide substrate (18).

Disease progression in MPS VI cats. In the colony maintained for these studies we have observed 38 MPS VI affected cats for various durations. Clinical presentation and severity were variable as reported previously $(25,26)$. At birth, MPS VI kittens were usually indistinguishable from their unaffected littermates, however a small proportion had lower birth weights. By 6-8 wk of age, features characteristic of MPS VI started to become discernible and were clearly apparent by 3 mo of age. Features included very mild corneal opacity, broad face with shortened nose, small ears, short neck and tail, reduced body length, and weight, abdominal distention, reduced flexibility of the cervical spine and coxofemoral joints, and variable degrees of pectus excavatum and kyphosis of the thoracolumbar spine. Permanent hindlimb neurological deficits of varying severity due to spinal cord compression were observed in $\sim 60 \%$ of untreated MPS VI cats with onset at 4-5 mo of age, compared with spinal cord dysfunction in $\sim 25 \%$ of MPS VI cats observed by Haskins et al. (25).

Enzyme administration and clinical evaluation in MPS VI cats. Three MPS VI cats were injected intravenously with two forms of rh4S (CHO and LEC) with therapy starting at between 2 and 12 mo, and in two cats with variable dose rates at different times (see Table III). An untreated MPS VI cat was included as a control.

In the last $4 \mathrm{mo}$ of therapy, premedication with $2 \mathrm{mg} / \mathrm{cat}$ of chlorpheniramine maleate (Niramine ${ }^{\circledR}$, Jurox Pty Ltd, Silverwater, NSW) was given to all cats subcutaneously (SC) prophylactically. Enzyme was infused in a volume of $2-10 \mathrm{mls}$ (diluted with PBS) into the cephalic vein over a period of 5-20 min. If signs suggestive of developing anaphylaxis occurred, enzyme infusion was stopped and reinstituted within $30 \mathrm{~min}$.

A clinical and neurological examination was done on a monthly basis, and slit lamp examinations of the corneas were performed in the conscious animals on three occasions (at 19, 20, and 23 mo in cats $\mathrm{A}$ and $\mathrm{B}$ and at 7, 8, and 11 mo in cat $\mathrm{C}$ ).

The following four standard radiographic views were taken of each cat: lateral cervical spine, lateral lumbar spine, lateral right hind limb, and ventrodorsal pelvis. These were done under general anesthesia (xylazine, Rompun ${ }^{\circledR}$ Bayer Australia Ltd Artarmon NSW, 1.1$2.2 \mathrm{mg} / \mathrm{kg} \mathrm{SC}$ and ketamine, Ketamine Injection ${ }^{\circledR}$ Parnell Laboratories (Aust.) Pty Ltd Alexandria NSW, 20-33 mg/kg SC) at three monthly intervals using detail intensifying screens at a constant focal film distance.

Urine samples were collected by manual bladder expression with xylazine sedation $(0.5 \mathrm{mg} / \mathrm{kg}$ intravenously (IV) or $1-2 \mathrm{mg} / \mathrm{kg} \mathrm{SC}$ ) or general anesthesia while undergoing radiological procedures. Samples were stored without preservative at $-20^{\circ} \mathrm{C}$ until assayed. Urine creatinine was assayed using an autoanalyzer method (Beckman Sychron $\mathrm{CX}^{\circledR}$ Systems). Total urine glycosaminoglycan content was quantitated using a modified alcian blue spectrophotometric method (27) and the concentration of urinary glycosaminoglycan in the sample was expressed as $\mathrm{mg} / \mathrm{mmol}$ creatinine. Densitometric estimations of the approximate relative proportions of dermatan sulfate were determined from high resolution electrophoresis on cellulose acetate strips (28). This was then used to calculate the dermatan sulfate content in the original urine sample.

Blood samples for determination of antibody titer to rh4S were collected on a monthly basis into EDTA or lithium heparin anticoagulant directly before enzyme administration. Plasma was separated by centrifugation ( $1600 \mathrm{~g}$ for $5 \mathrm{~min}$ ) at room temperature. On one occasion plasma samples were collected from cat A before rh4S infusion, then at 30 and 60 min post infusion and processed as above. Samples were stored at $-20^{\circ} \mathrm{C}$ until assayed. An ELISA assay using 96-well polyvinylchloride plates precoated with purified $\mathrm{rh} 4 \mathrm{~S}$ and an anti-cat horseradish peroxidase-labeled secondary antibody was used to titrate out antibodies to rh4S in the plasma samples (unpublished method).

To determine the effect of the high antibody titer feline plasma (from cat A) on rh4S activity, constant amounts of rh4S were titrated against feline plasma and a control rabbit anti-4-sulfatase polyclonal antisera, and the 4-sulfatase activity of the resulting complex measured by MUS substrate reaction. Various amounts of plasma from cat A, or rabbit anti-4-sulfatase polyclonal antibody (29) $(0,1,5,10$, 15 , and $20 \mu \mathrm{l}$ of antibody) were added to $50 \mathrm{nmol} / \mathrm{min} / \mathrm{ml}$ of $\mathrm{rh} 4 \mathrm{~S}$ in 
$0.02 \mathrm{M}$ Tris $/ \mathrm{HCl}$, pH 7.0 containing $0.25 \mathrm{M} \mathrm{NaCl}$ and $1 \%$ (wt/vol) ovalbumin, in a total volume of $40 \mu \mathrm{l}$ and incubated at $4^{\circ} \mathrm{C}$ for $2 \mathrm{~h} .100$ $\mu l$ of MUS substrate $(5 \mathrm{mM})$ was added to each sample and incubated at $37^{\circ} \mathrm{C}$ for $20 \mathrm{~min}(18)$. To determine 4-sulfatase activity the level of substrate conversion (release of methylumbelliferone) was measured in a Perkin-Elmer spectrofluorometer at $446 \mathrm{~nm}$ using an excitation wavelength of $366 \mathrm{~nm}$. Results were expressed as activity units in $\mathrm{nmol} / \mathrm{min}$ per $\mathrm{ml}$.

Skin biopsies were taken from cats A and B at 9 mo of age under general anesthesia. This was 7 wk after onset of enzyme administration in cat A. This was repeated in both cats at 12 mo of age, before the onset of enzyme administration in cat B.

Cats $\mathrm{A}$ and $\mathrm{B}$ were killed at $27 \mathrm{mo}, 7 \mathrm{~d}$ after last enzyme injection, and cat $\mathrm{C}$ at $15 \mathrm{mo}, 4 \mathrm{~d}$ after last enzyme injection, using an overdose of IV barbiturate. Tissues were collected (whole organs where possible) and weighed for determination of rh4S distribution then frozen at $-20^{\circ} \mathrm{C}$ until assayed. Samples were also taken for light and electron microscopy. For light microscopy, tissues were fixed in $10 \%$ formalin for 3-6 h then transferred into 70\% alcohol and were processed and stained with hematoxylin and eosin routinely within $96 \mathrm{~h}$. Electron microscopy samples were minced to $1 \mathrm{~mm}^{3}$ or less and fixed in $1 \%$ glutaraldehyde $/ 4 \%$ formalin in $0.1 \mathrm{M}$ sodium cacodylate buffer $\mathrm{pH} 7.2$ for $2-3 \mathrm{~h}$ at room temperature then postfixed in $1 \%$ osmium tetroxide, dehydrated and embedded in Spurrs resin. 1- $\mu$ m-thick sections were stained with toluidine blue and then ultrathin sections stained with $2 \%$ uranyl acetate $/ 1 \%$ lead citrate and examined with a Hitachi H-7000 electron microscope. An untreated MPS VI cat and a normal cat were killed at $30 \mathrm{mo}$ of age and were used as controls for light and electron microscopy. The L5 vertebra was also removed, fixed in $10 \%$ formalin and embedded in methylmethacrylate resin before sectioning using routine methods. Undecalcified tissue sections $(7 \mu \mathrm{m})$ were stained with von Kossa to visualize mineralized bone. Sections were visually scanned to ensure integrity. Each vertebra was analyzed at a magnification of $\times 46$ using an automated image analysis system (Quantimet 520 system, version 4.0; Cambridge Instruments). Mean values were calculated for each vertebra. Bone volume, trabecular number and trabecular spacing were calculated using standard morphometric formulae (30).

Distribution studies. Seven normal cats (12-24 mo old) were sedated with $0.25 \mathrm{mg}$ atropine sulfate and $0.5 \mathrm{mg}$ acepromazine maleate SC (Anamav ${ }^{\circledR}$; Mavlab Pty Ltd., Slacks Creek, Qld, Australia). Anesthesia was induced by IV Saffan ${ }^{\circledR}$ (alphaxalone $9 \mathrm{mg} / \mathrm{ml}$ and alphadolone acetate $3 \mathrm{mg} / \mathrm{ml}$; Jurox Pty Ltd., Silverwater, NSW, Australia at $\sim 9 \mathrm{mg} / \mathrm{kg}$ ) and maintained on halothane. The femoral artery was cannulated using polyethylene tubing (PE 50; Dural Plastics and Engineering, Auburn, NSW, Australia) attached to a three-way tap filled with heparinized saline. Purified $\mathrm{rh} 4 \mathrm{~S}$ at dose $1 \mathrm{mg} / \mathrm{kg}$ (CHO, LEC, and LEC-P) or $\sim 7.5 \mathrm{mg} / \mathrm{kg}$ (CHO at $7.3 \mathrm{mg} / \mathrm{kg}$ and LEC at $7.95 \mathrm{mg} / \mathrm{kg}$ ) was infused into the cephalic vein in a volume of $7 \mathrm{ml}$ over $40 \mathrm{~s}$, with time zero taken from $20 \mathrm{~s}$. Serial 1-ml heparinized blood samples were collected from the femoral artery for up to $2 \mathrm{~h}$ after enzyme infusion. Samples were centrifuged (1600 $g$ for $3 \mathrm{~min}$ ) at $20^{\circ} \mathrm{C}$ within $2-5 \mathrm{~min}$ of sampling, plasma collected and the buffy layer was removed and immediately washed by resuspending in saline. The buffy layer samples were recentrifuged (as above) and then separated from any contaminating red blood cells using dextran sedimentation (31) within 2-4 h of sampling. Buffy layer and plasma samples were then stored at $-20^{\circ} \mathrm{C}$ until assayed. Polyethylene tubing and threeway taps were flushed with heparinized saline between sampling times. After $4 \mathrm{~h}$, cats were killed using an overdose of intravenous barbiturate. Tissues were collected (whole organs where possible), weighed and then frozen at $-20^{\circ} \mathrm{C}$ until assayed.

Three normal cats (8-66 mo old) were injected intravenously with $7 \mathrm{ml} \mathrm{CHO} \mathrm{rh} 4 \mathrm{~S}$ at $1 \mathrm{mg} / \mathrm{kg}$ at 2, 4, and $7 \mathrm{~d}$ before killing. One additional normal cat was used for detection of $\mathrm{f} 4 \mathrm{~S}$ levels in tissues and was not exposed to rh4S. Killing and tissue collection was performed as above.

Tissue preparation and analysis. Preparation of tissue extracts, detection of rh4S in feline tissues, white cells and plasma, and detection of $\mathrm{f} 4 \mathrm{~S}$ in normal control cat tissues were according to methods described previously (24). Briefly, this involved binding sheep antimouse immunoglobulin to a 96-well polyvinylchloride plate, then adding a second layer of either a human specific monoclonal antibody (F66) to detect rh4S, or a polyclonal anti-h4S antibody (that cross reacts with f4S) to detect f4S. Tissue extracts were then applied to the plates and MUS substrate used to determine rh4S/f4S activity fluorometrically. Limits of detection for the assay were $4.5 \times 10^{-3} \mathrm{nmol} /$ min. During the development of this assay procedure, a nondialyzable inhibitor of $4 \mathrm{~S}$ activity was shown to be present in cat liver (24). The method clearly overcame the influence of this inhibitor.

\section{Results}

Distribution in normal cats infused with rh4S. Three forms (CHO, LEC, and LEC-P) of rh4S with different glycosylation structures were evaluated for plasma half-life and tissue distribution. At $1 \mathrm{mg} / \mathrm{kg}$, LEC rh4S was cleared from circulation by 20-30 min (Fig. 1), as was CHO and LEC-P (data not shown). At $\sim 7.5 \mathrm{mg} / \mathrm{kg}$ there was a dose dependent clearance of $\mathrm{CHO}$ rh4S (Fig. 1) and LEC rh4S (data not shown), with rh4S activity in plasma detectable for up to $120 \mathrm{~min}$. Plasma half-life for all forms of rh $4 \mathrm{~S}$ at $1 \mathrm{mg} / \mathrm{kg}$ was $13.7 \pm 3.2 \mathrm{~min}$, and for $\mathrm{CHO}$ and LEC rh $4 \mathrm{~S}$ at $\sim 7.5 \mathrm{mg} / \mathrm{kg}$ was approximately $45 \mathrm{~min}$. At either dose, and for all three forms, rh4S could not be detected in peripheral blood leukocytes.

$4 \mathrm{~h}$ after administration of $1 \mathrm{mg} / \mathrm{kg}$, the tissue distribution of all forms of rh4S was similar (Table I) with the majority of the infused rh4S found in the liver. Significant levels of rh4S were also observed in spleen, lung, kidney, heart, skin, aorta, cerebrum, cerebellum, and lymph node compared to $44 \mathrm{~S}$ levels in a normal control (Tables I and II). Increased dose resulted in a proportional increase in levels of rh4S in all tissues.

Minor differences were noted in the distribution pattern for $\mathrm{CHO}$ and LEC rh4S. Proportionally more CHO rh4S was detected in lung (ninefold) and skin (twofold), whereas LEC rh4S activity was detectable in cartilage and cornea (Table II). Dephosphorylation of rh4S (LEC-P) resulted in lower enzyme activities in all tissues, however the pattern of distribution remained consistent (Table II). Uptake studies in the THP-1 monocyte cell line (American Type Culture Collection, Rockville, MD) demonstrated uptake of LEC rh4S was completely

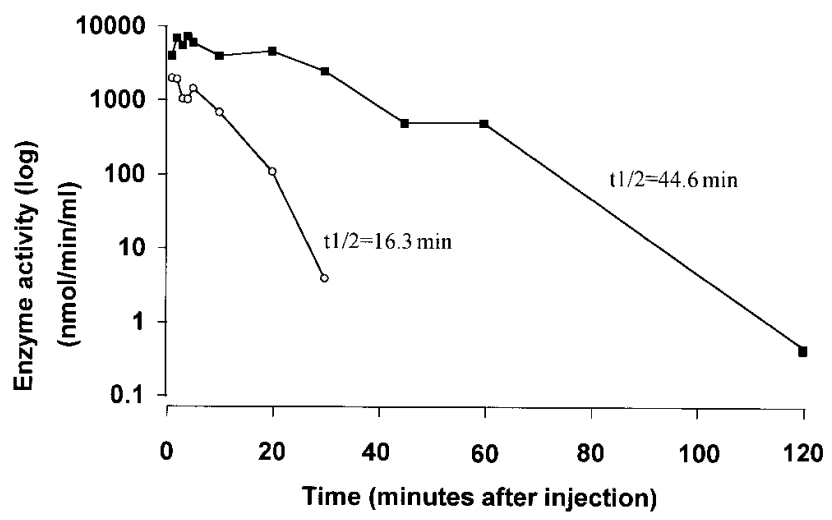

Figure 1. Plasma clearance of rh4S in normal anesthetised cats in serial arterial blood samples after intravenous administration of $1 \mathrm{mg} /$ $\mathrm{kg} \mathrm{LEC} \mathrm{rh} 4 \mathrm{~S}(\mathrm{O})$ and $7.5 \mathrm{mg} / \mathrm{kg} \mathrm{CHO} \mathrm{rh} 4 \mathrm{~S}(\mathbf{\square})$. 
Table I. Tissue Enzyme Activity of (nmol/min/gram tissue) CHO, LEC, and LEC-P rh $4 S$ at Two Doses, $4 \mathrm{~h}$ after Intravenous Infusion, Compared with f4S Activity in a Normal Control Cat

\begin{tabular}{lcccccc}
\hline \multicolumn{1}{c}{ rh4S type } & $\begin{array}{c}\text { CHO } \\
n=3\end{array}$ & $\begin{array}{c}\text { CHO } \\
n=1\end{array}$ & $\begin{array}{c}\text { LEC } \\
n=1\end{array}$ & $\begin{array}{c}\text { LEC } \\
n=1\end{array}$ & $\begin{array}{c}\text { LEC-P } \\
n=1\end{array}$ & $\begin{array}{c}\text { Normal } \\
(\mathrm{f} 4 \mathrm{n})^{\sharp}\end{array}$ \\
\hline \multicolumn{1}{c}{ dose } & $1 \mathrm{mg} / \mathrm{kg}$ & $7.3 \mathrm{mg} / \mathrm{kg}^{\ddagger}$ & $1 \mathrm{mg} / \mathrm{kg}$ & $7.95 \mathrm{mg} / \mathrm{kg}^{\ddagger}$ & $1 \mathrm{mg} / \mathrm{kg}$ & None \\
& & & & & & \\
Liver* & $2526 \pm 1435$ & 1229 & 1407 & 1691 & 701 & 5.1 \\
Spleen & $61 \pm 20$ & 15.4 & 46 & 80.5 & 10 & 10.2 \\
Lung & $29 \pm 15$ & 15.4 & 1.8 & 5.9 & 3.2 & 1.3 \\
Kidney & $15 \pm 6.6$ & 15.4 & 18 & 23 & 13 & 1.3 \\
Heart & $2.6 \pm 2.2$ & 1.6 & 0.9 & 0.4 & 3.2 & 0.6 \\
Skin & $1.25^{\S}$ & 0.7 & 0.7 & 0.3 & 0.5 & 0.04 \\
Aorta & $1.18 \pm 1.02$ & 0.3 & 3.1 & 0.2 & 2.2 & 0.3 \\
Cerebrum & $0.17^{\S}$ & 2.2 & 0.4 & 0.1 & 0 & 6.4 \\
Cerebellum & $0.5^{\S}$ & 0.2 & 1.5 & 0.1 & 0 & 10.2 \\
Cartilage & $0^{\S}$ & 0.01 & 0.1 & 0.01 & 0 & 1.12 \\
Cornea & $0^{\S}$ & 1.3 & 0.2 & 0.05 & 0 & 0.1 \\
Lymph node & $26 \pm 43$ & 176 & 21 & 19.4 & 1.1 & 1.3 \\
& & & & & & \\
\hline
\end{tabular}

$\pm 1 \mathrm{SD} ;{ }^{\ddagger}$ corrected to $1 \mathrm{mg} / \mathrm{kg} ;{ }^{\S}(n=2) ;{ }^{\circledR} \mathrm{f} 4 \mathrm{~S}$ activity measured as described in Methods. *Note: for liver values only, an average of $330 \%$ of total enzyme injected is recovered (range, 140-740\%) when calculated from original organ weights. The reason for this is not fully understood, but factors include variable specific activity measurements of the original enzyme and altered enzyme activity due to dilution in liver tissue extracts.

inhibited by mannose-6-phosphate whereas uptake of LEC-P rh4S was not observed into these cells (data not shown).

Tissue half-life evaluated for $\mathrm{CHO}$ rh4S only, was estimated to be 2-4 d in liver, spleen, lung, kidney and heart (Fig. 2, $A, B$, and $C$ ). At $1 \mathrm{mg} / \mathrm{kg}$, low but detectable levels of $\mathrm{CHO}$ rh4S were observed in liver, spleen, lung, and kidney $7 \mathrm{~d}$ after infusion (Figs. 2, $A, B$, and $C$ ), but rh4S was not detectable in heart, skin, aorta and brain (data not shown).

Disease progression in MPS VI cats undergoing ERT. Three MPS VI cats (A, B, and C) were treated with two forms of rh4S, with the onset of therapy at different ages according to the protocol (Table III).

Table II. Ratio of Tissue Activity of CHO, LEC, and LEC-P rh $4 S$ at $1 \mathrm{mg} / \mathrm{kg}$, $4 \mathrm{~h}$ after Infusion, to f4S Activity in a Normal Control Cat

\begin{tabular}{lccc}
\hline & Ratio CHO rh4S/f4S & Ratio LEC rh4S/f4S & Ratio LEC-P rh4S/f4S \\
\hline Liver & 495.3 & 275.9 & 137.5 \\
Spleen & 6.0 & 4.5 & 1 \\
Lung & 22.3 & 1.4 & 2.5 \\
Kidney & 11.5 & 13.8 & 10 \\
Heart & 4.3 & 1.5 & 5.3 \\
Skin & 31 & 17.5 & 12.5 \\
Aorta & 4 & 10.3 & 7.3 \\
Cerebrum & 0.03 & 0.06 & - \\
Cerebellum & 0.05 & 0.15 & - \\
Cartilage & $\$$ & 0.09 & - \\
Cornea & & 2 & 0.8 \\
Lymph node & 20 & 16.2 & - \\
\hline
\end{tabular}

${ }^{\S}$ Ratio not calculable due to value of numerator being equal to zero.
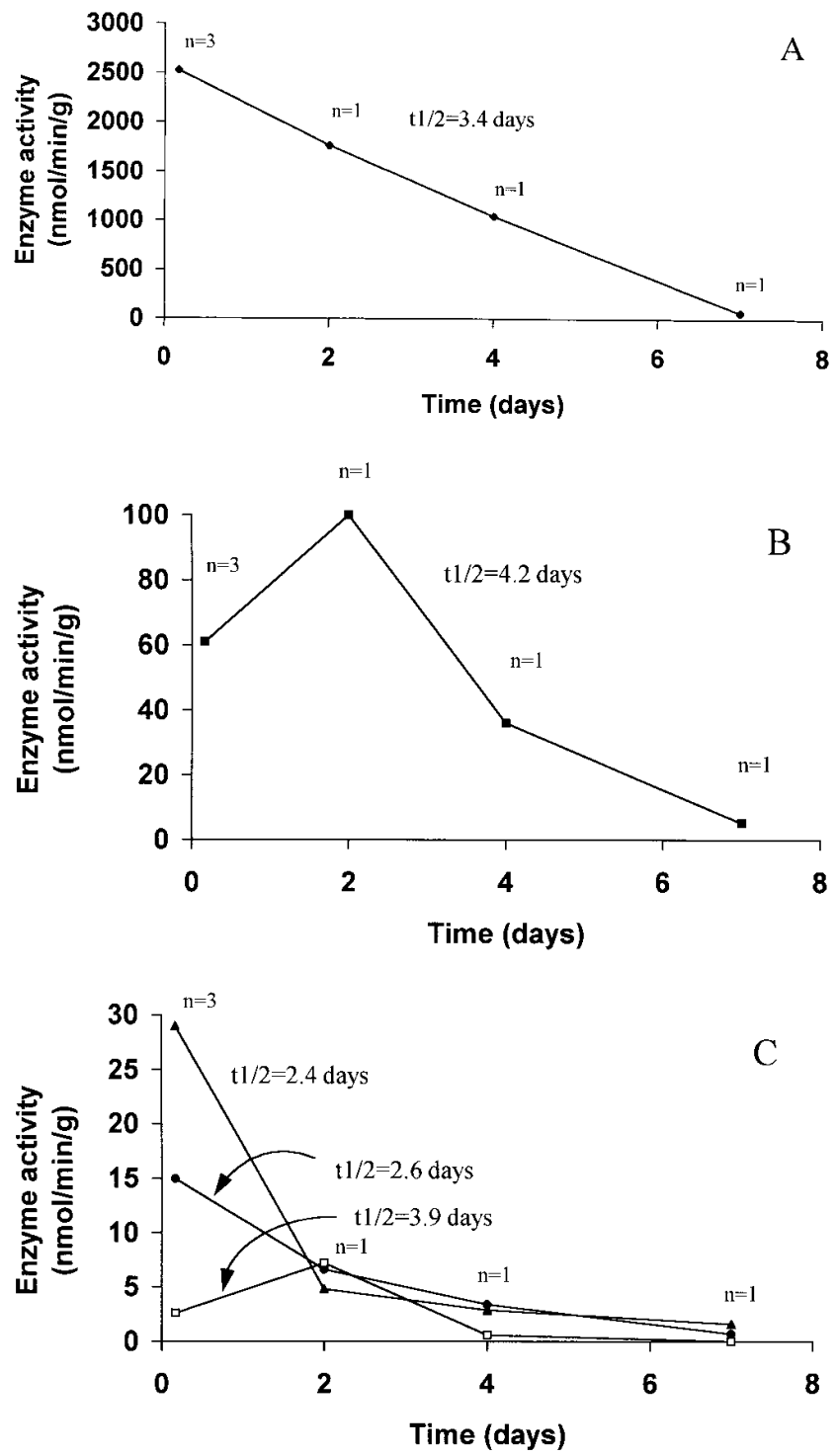

Figure 2. (A) Fate of $\mathrm{CHO}$ rh4S in the liver $(\bullet)$ of normal cats up to $7 \mathrm{~d}$ after intravenous administration of $1 \mathrm{mg} / \mathrm{kg}$. (B) Fate of CHO $\mathrm{rh} 4 \mathrm{~S}$ in the spleen $(\mathbf{\square})$ of normal cats up to $7 \mathrm{~d}$ after intravenous administration of $1 \mathrm{mg} / \mathrm{kg}$. (C) Fate of CHO rh $4 \mathrm{~S}$ in lung $(\boldsymbol{\Lambda})$, kidney $(\bullet)$ and heart ( $\square$ ) of normal cats up to $7 \mathrm{~d}$ after intravenous administration of $1 \mathrm{mg} / \mathrm{kg}$.

In cat $\mathrm{A}$, mild hindlimb paresis was evident by 4 mo which progressed to almost complete hindlimb paralysis with hypertonicity and extension of the hindlimbs by 7 mo. Localization of the upper motor neuron lesion was not performed. ERT was instituted at $7 \mathrm{mo}$ as an alternative to killing. After $4 \mathrm{wk}$, cat A was very mobile and using hindlimbs normally although no neurological examination was performed. By 10 mo, cat A deteriorated exhibiting progressive hindlimb paresis eventuating in absence of extensor postural thrust. At 16 mo mobility and proprioception was unexpectedly improved in hindlimbs, with presence of extensor postural thrust, patellar hyperreflexia, delayed proprioceptive positioning, and a staggery unsteady gait. In subsequent months, use of his hindlimbs and presence of extensor postural thrust was intermittent/variable but improved mobility with greatly increased activity occurred 
Table III. Age at Onset of ERT, Dose Regime and rh4S Form Used in MPS VI Cats A, B, and C

\begin{tabular}{lccccc}
\hline & Cat A & Cat A & Cat B & Cat B & Cat C \\
\hline Enzyme form & CHO rh4S & CHO rh4S & LEC rh4S & LEC rh4S & CHO rh4S \\
Dose & $0.8 \mathrm{mg} / \mathrm{kg}$ per $14 \mathrm{~d}$ & $1.5 \mathrm{mg} / \mathrm{kg}$ per $7 \mathrm{~d}$ & $0.5 \mathrm{mg} / \mathrm{kg} \mathrm{per} 14 \mathrm{~d}$ & $1.4 \mathrm{mg} / \mathrm{kg} \mathrm{per} 7 \mathrm{~d}$ & $0.8 \mathrm{mg} / \mathrm{kg} \mathrm{per} \mathrm{14} \mathrm{d}$ \\
Age at dose (months) & $7 *-22$ & $22-27$ & $12^{*}-23$ & $23-27$ & $2 *-15$ \\
\hline
\end{tabular}

*Age at onset of ERT.

at $22 \mathrm{mo}$ after increasing the enzyme dose to $2 \mathrm{mg} / \mathrm{kg}$. Cat B did not appear to develop any neurological deficits, although gait and mobility were altered due to progression of skeletal disease. Cat B remained the most mobile of all three cats. ERT started at 2 mo of age in cat $\mathrm{C}$, at which time only mild features of MPS VI were evident. Very mild hindlimb paresis was first noticed at 6 mo and progressed marginally such that the extensor postural thrust was slightly slower than normal. By 9 mo cat $\mathrm{C}$ was usually sedentary and the most inactive of the three, but was still able to walk reasonably well with a paretic gait.

Slit lamp examination of the corneas of all three cats showed a mild degree of corneal opacity which did not change during therapy. Radiographic changes in all three cats were similar to the MPS VI cats described by Konde et al. (26), with epiphyseal dysplasia resulting in severe degeneration of vertebral bodies particularly in the cervical spine, hypoplasia and fragmentation of the dens, small deformed proximal humeral, distal femoral, and proximal and distal tibial epiphyses, coxofemoral subluxation and remodeling of the acetabula and femoral heads, pectus excavatum, and reduced cortical thickness of long bones. Moderate to severe kyphosis of the lumbar spine occurred in all three cats. All lesions progressed with age. There were no significant radiographic improvements in the skeletal pathology of all three treated cats after treatment.

Bone morphometry. Parameters of trabecular bone development were determined from the fifth lumbar (L5) vertebra. Bone mineral volume correlated with age of onset of therapy, and in cat $\mathrm{C}$ (onset of ERT at $2 \mathrm{mo}$ ) bone volume was closest to that of normal cat vertebra, compared with cat A (onset of ERT at $7 \mathrm{mo}$ ). Bone volume in cat B, in which therapy was initiated after skeletal maturity (onset of ERT at $12 \mathrm{mo}$ ) was no different from untreated MPS VI cat D (Table IV). Trabecular number was improved in all the treated cats and showed the same trend associated with the age of onset of ERT, but values were still less than the normal control. Trabecular spacing was

Table IV. Morphometric Analysis of the Fifth Lumbar Vertebra in a Normal Cat, Treated MPS VI Cats A, B, and C, and Untreated Cat D

\begin{tabular}{lccccc}
\hline & Normal & Cat A & Cat B & Cat C & Cat D \\
\hline BV/TV & 23.8 & 9.6 & 5.0 & 12.2 & 5.5 \\
Tb.Sp. & 0.89 & 0.94 & 0.96 & 0.94 & 0.96 \\
Tb.N. & 2.2 & 1.6 & 1.2 & 2.0 & 1.0 \\
Age (mo) & 30 & 27 & 27 & 15 & 30 \\
\hline
\end{tabular}

${ }^{\S}$ Bone volume/total volume (\%); ${ }^{\ddagger}$ trabecular spacing $(\mathrm{mm}) ;{ }^{\natural}$ trabecular number (number/mm). also improved in cats treated prior to skeletal maturity (cats A and $\mathrm{C}$, Table IV).

Antibody response. All cats exhibited restlessness, trembling, and increased respiratory rate to varying extents, indicating possible development of hypersensitivity, but none developed typical anaphylactic reactions during therapy. Antibody titers tended to increase after the initiation of ERT, and ranged up to $1,024,000$ in cat $\mathrm{A}, 64,000$ in cat $\mathrm{B}$, and 64,000 in cat $\mathrm{C}$. Titers fluctuated after reaching high levels, and did not appear to correlate with clinical appearance of the treated cats, such as improved or reduced mobility. Values in age matched untreated normal control cats ranged from 4,096-32,000. Therefore only cat A showed antibody titers significantly above the control.

In an experiment 8 mo after onset of therapy, administration of rh4S to cat $\mathrm{A}$ resulted in a reduction in antibody titer from $>512,000$ before rh4S infusion, to 2,048 by $30 \mathrm{~min}$ and 1,024 by 60 min after rh $4 \mathrm{~S}$ infusion.

Inhibition of rh4S activity by plasma from a high titer cat. Plasma from cat A (titer 1,024,000) and a specific 4-sulfatase rabbit polyclonal were able to inhibit the activity of rh4S in a dose dependent manner. The addition of the same amounts of fetal bovine serum to rh4S had no detectable effect on 4-sulfatase activity (Fig. 3).

Urinary glycosaminoglycans. At $400 \mathrm{~d}$ of age, the total glycosaminoglycan content in the urine of treated MPS VI cat A was approximately midway between that of the normal control cats and the untreated MPS VI cat D (Fig. $4 A$ ), and in treated cats $\mathrm{B}$ and $\mathrm{C}$ was approximately equal to that of the normal

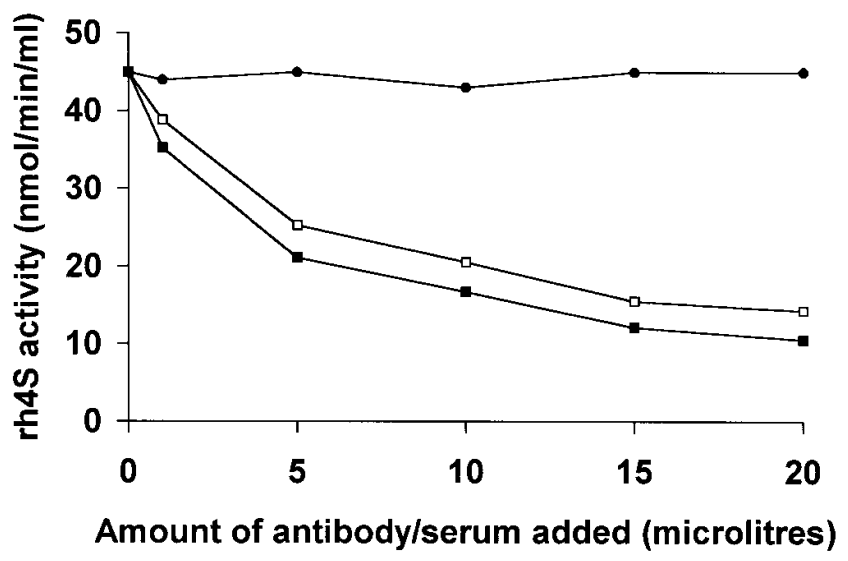

Figure 3. Inhibition of 4-sulfatase activity by high titer feline plasma (cat A, - ) and rabbit anti-human 4-sulfatase polyclonal antibody $(\square)$, compared with fetal bovine serum $(\bullet)$ (nonimmune serum). 

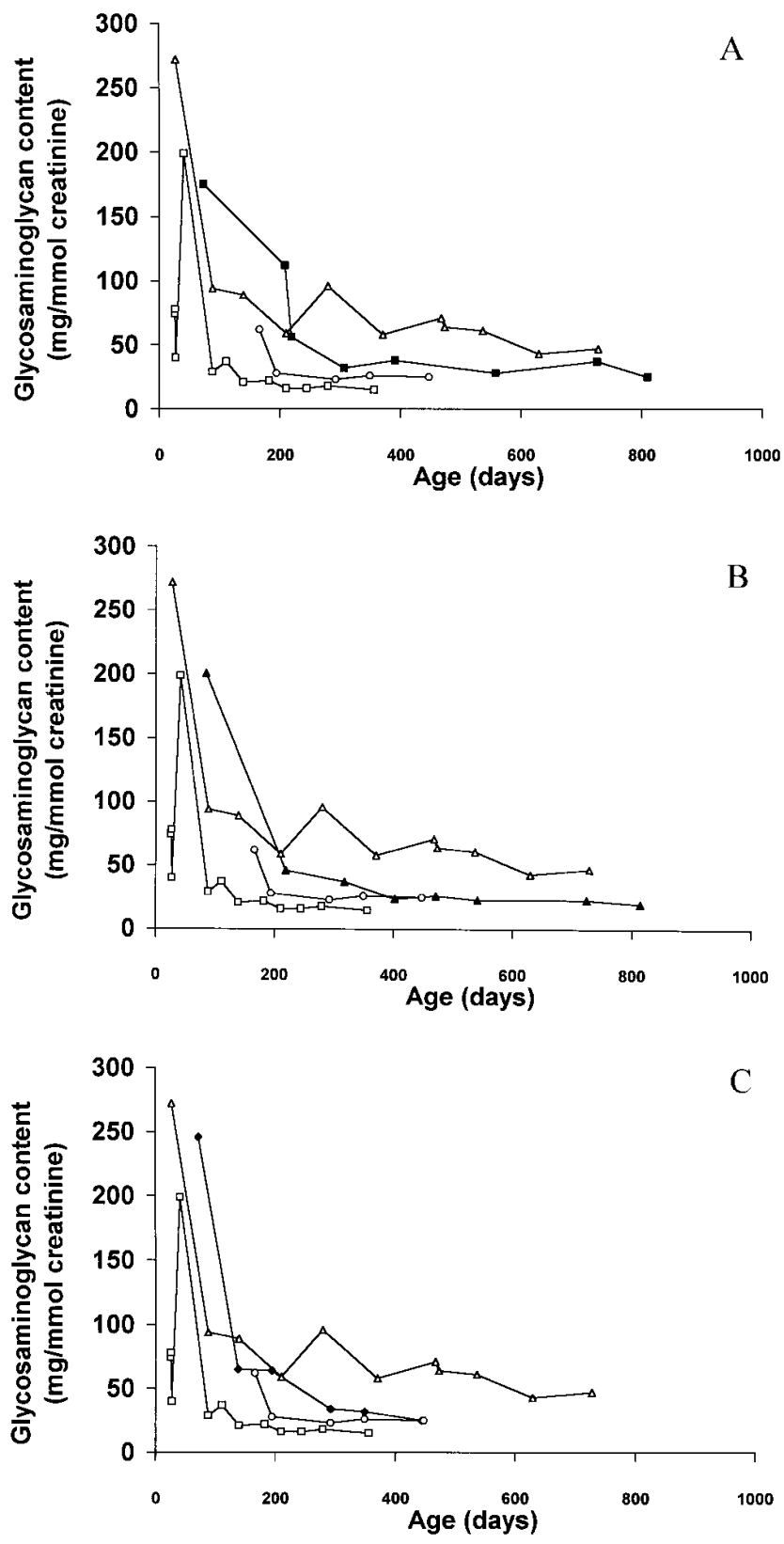

Figure 4. Total urinary glycosaminoglycan excretion in $(A)$ cat $\mathrm{A}$ $(\mathbf{\square}),(B)$ cat B $(\mathbf{\Delta})$, and $(C)$ cat $\mathrm{C}(\diamond)$, undergoing ERT compared with a normal female $(\square)$, normal male $(\bigcirc)$, and untreated MPS VI cat $\mathrm{D}(\triangle)$.

control cats (Fig. 4, $B$ and $C$ ). At just under $400 \mathrm{~d}$ of age, the urine dermatan sulfate content from cats $\mathrm{A}, \mathrm{B}$, and $\mathrm{C}$ was approximately midway between that of the untreated MPS VI cat $\mathrm{D}$ and the normal control cats. Cats $\mathrm{A}$ and $\mathrm{B}$ had slightly higher dermatan sulfate levels than cat $\mathrm{C}$ (Fig. 5, $A, B$, and $C$ ).

Gross pathology. Cats A, B, and C all developed physical features consistent with untreated MPS VI cats observed in the colony. Abdominal distention was prominent in cats $\mathrm{A}$ and $\mathrm{C}$ due to the shortened body length. Cats $\mathrm{A}, \mathrm{B}$, and $\mathrm{C}$ weighed $2.8,3.0$, and $2.5 \mathrm{~kg}$, respectively, at death compared with a normal adult male weight range of 4-7 kg.

The abdominal organs of all three cats appeared normal, with no evidence of hepatomegaly. Heart valves in all three
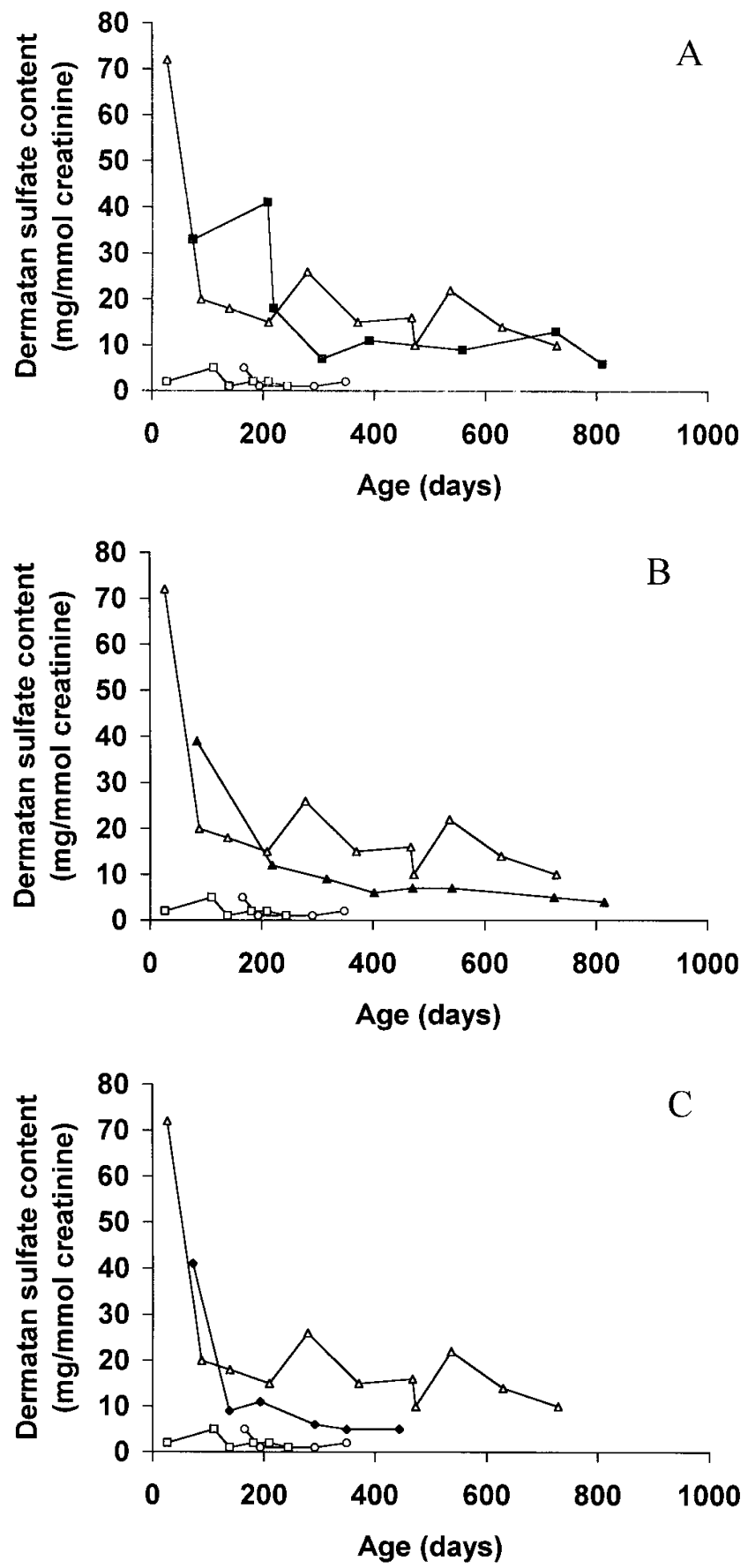

Figure 5. Urinary dermatan sulfate in $(A)$ cat $\mathrm{A}(\mathbf{\square}),(B)$ cat $\mathrm{B}(\boldsymbol{\Delta})$, and $(C)$ cat $\mathrm{C}(\diamond)$, undergoing ERT compared with a normal female $(\square)$, normal male $(\bigcirc)$, and untreated MPS VI cat $\mathrm{D}(\triangle)$.

cats were not grossly thickened compared with normal cats. There was diffuse or irregular whiteness of articular cartilage due to variable cartilage thickness in the femorotibial, coxofemoral and shoulder joints. Cartilage also appeared loosely attached and was easily removed from the subchondral bone in cats $\mathrm{A}$ and $\mathrm{B}$. In cat $\mathrm{A}$ there was evidence of cartilage flap formation in one femoral head and in one humeral head. Underlying subchondral bone appeared white and avascular and in many areas, plugs of cartilage remained in subchondral bone. The articular surface of the proximal humerus also had 
severe focal erosion of cartilage down to subchondral bone. The distal femur had undergone moderate remodeling in cats $\mathrm{B}$ and $\mathrm{C}$. The spinal cord was exposed from the $\mathrm{C} 2$ to $\mathrm{L} 4$ vertebral level and mild compression was present in the C7/T1 to $\mathrm{T} 2 / 3$ region only in cat $\mathrm{C}$.

\section{Discussion}

With the anticipation of ERT clinical trials with rh4S in human MPS VI patients, the aim of the experiments reported here was to evaluate distribution and fate of three variably glycosylated forms of rh4S and the efficacy of therapy with two of these forms in 4-sulfatase deficient MPS VI cats.

$4 \mathrm{~h}$ after infusion of $1 \mathrm{mg} / \mathrm{kg} \mathrm{CHO}$ rh $4 \mathrm{~S}$, enzyme activity was highest in the liver followed by spleen, lung and kidney, with levels of rh $4 \mathrm{~S}$ in these tissues above the level of $\mathrm{f} 4 \mathrm{~S}$ in a normal control cat. Trends observed in tissue distribution were comparable to those found in $\beta$-D-glucuronidase infused MPS VII mice (14) $\beta$-D-hexosaminidase infusion into normal cats (32), and $\alpha$-L-iduronidase infusion into MPS I dogs (16). These studies showed highest levels of infused lysosomal enzymes in the liver followed generally by spleen then lung or kidney then heart.

Although the glycosylation structures were not characterized, $\mathrm{CHO}$ rh4S is thought to have undergone complex oligosaccharide modifications and phosphorylation of terminal mannose structures. Conversely high mannose structures of LEC rh4S have undergone phosphorylation but no complex oligosaccharide modifications. The mannose-6-phosphate receptor which recognizes phosphomannosyl terminating oligosaccharides, is involved in lysosomal enzyme targeting and is found in many cell types including fibroblasts, myoblasts and hepatocytes $(33,34)$. Other cell surface receptors recognizing different carbohydrate structures include the mannose $/ N$ acetylglucosamine receptor found in tissue macrophages and the asialogalactose receptor in hepatocytes (34).

In these studies, CHO, LEC and LEC-P rh4S produced only minor differences in uptake, with the overall pattern of distribution being similar for each form. CHO and LEC rh4S may have used the mannose-6-phosphate receptor for cell uptake however other receptors may also have been involved. LEC and $\mathrm{CHO}$ rh4S were taken up by different receptors on rat lung macrophages and it was hypothesized that different uptake mechanisms reflected altered carbohydrate structures on each rh4S form utilizing different cell surface receptors (M. Fuller, unpublished observations). Consistent with the report of Van der Ploeg et al. (35), that dephosphorylation of $\alpha$-glucosidase completely inhibited uptake into skeletal and heart muscle after intravenous administration to mice, LEC-P rh4S appears to have reduced efficiency of enzyme uptake with lower enzyme activities in tissues.

The minor differences in tissue distribution between $\mathrm{CHO}$ and LEC rh4S did not appear to significantly alter the degree of lysosomal vacuolation in the tissues of treated cats. Normalization of morphology in Kupffer cells (Fig. 6) has been demonstrated in other animal models undergoing ERT $(14,16)$. The significant reduction in storage vacuoles in renal interstitial fibroblasts (Fig. 7) was not observed in MPS I dogs that underwent ERT (16). This may have been due to the lower dosage rates used in the MPS I dogs. Our study suggests that skin biopsies may be a useful way of monitoring response to ERT (Fig. 8). Reduction in lysosomal storage in dermal fibroblasts was also observed by Navarro et al. (36) in a MPS I patient who had undergone bone marrow transplantation 21 mo earlier. Lack of correction of storage seen clinically in the corneas and demonstrated by electron microscopy in the chondrocytes (Fig. 9) correlates with the results of our distribution studies, as well as studies of ERT in other animal models $(14,16)$. The reduction in urinary dermatan sulfate, although not completely normalized, correlated with the reduction in vacuolation seen in most tissues examined.

The estimated half-life of rh $4 \mathrm{~S}$ in cultured fibroblasts was 7-14 d (37) and this value was used to decide on the initial dose frequency in all three treated cats. However the half-life of $\mathrm{CHO}$ rh4S ranged from $2-4 \mathrm{~d}$ in selected tissues, suggesting that the 7-d dose interval in cats A and B was more appropriate, than the two week interval used initially in cats A and B,
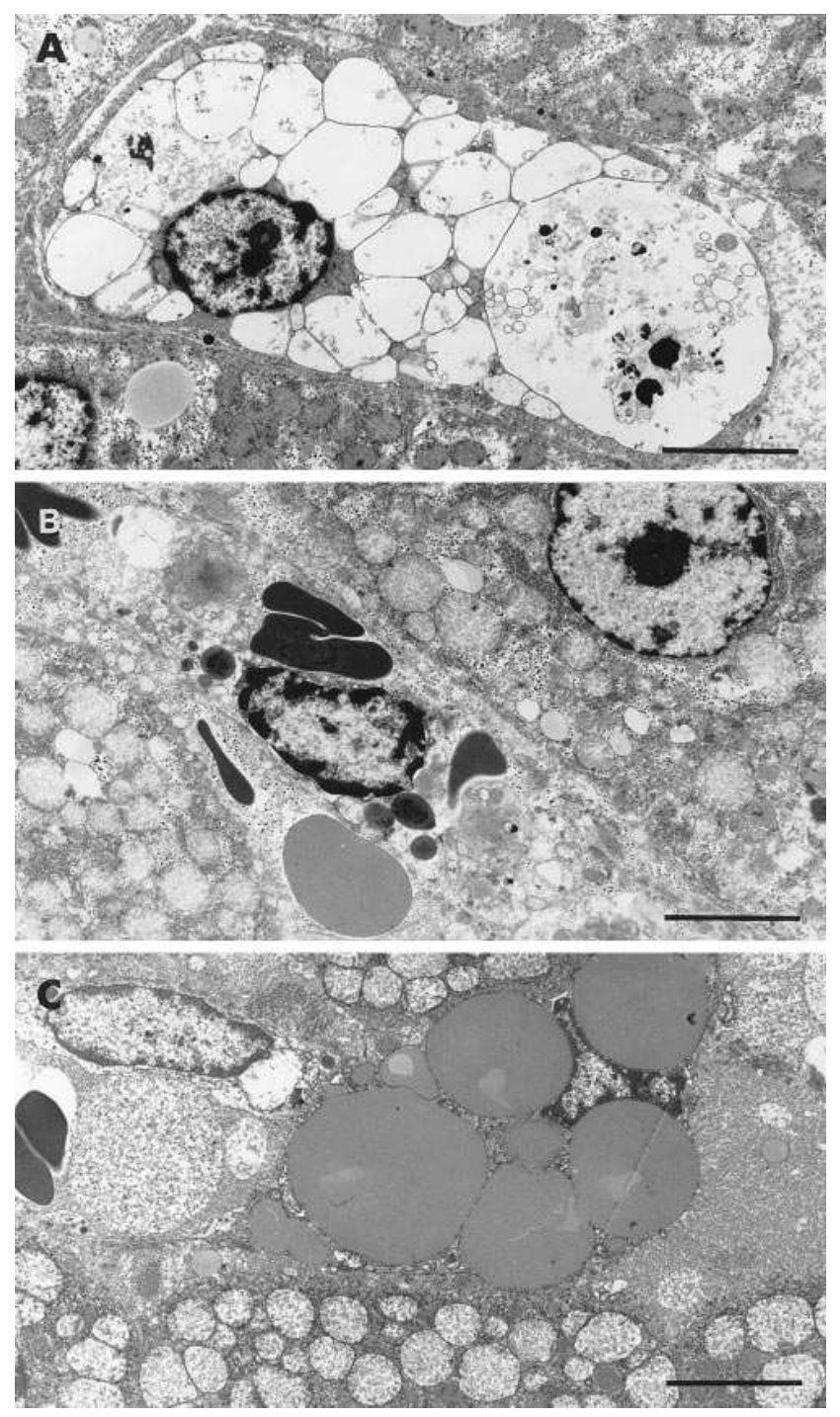

Figure 6. Electron microscopy of Kupffer cells in liver showing $(A)$ numerous enlarged lysosomes in a 15-mo-old untreated control MPS VI cat, $(B)$ normalization of morphology in cat $C$, and $(C)$ lipid vacuolation and absence of enlarged lysosomes in cat B. Compared with the untreated MPS VI control there was a dramatic clearance of storage in Kupffer cells in the three treated cats and these cells appeared normal (cat A, data not shown). Bar, $2 \mu \mathrm{m}$. 

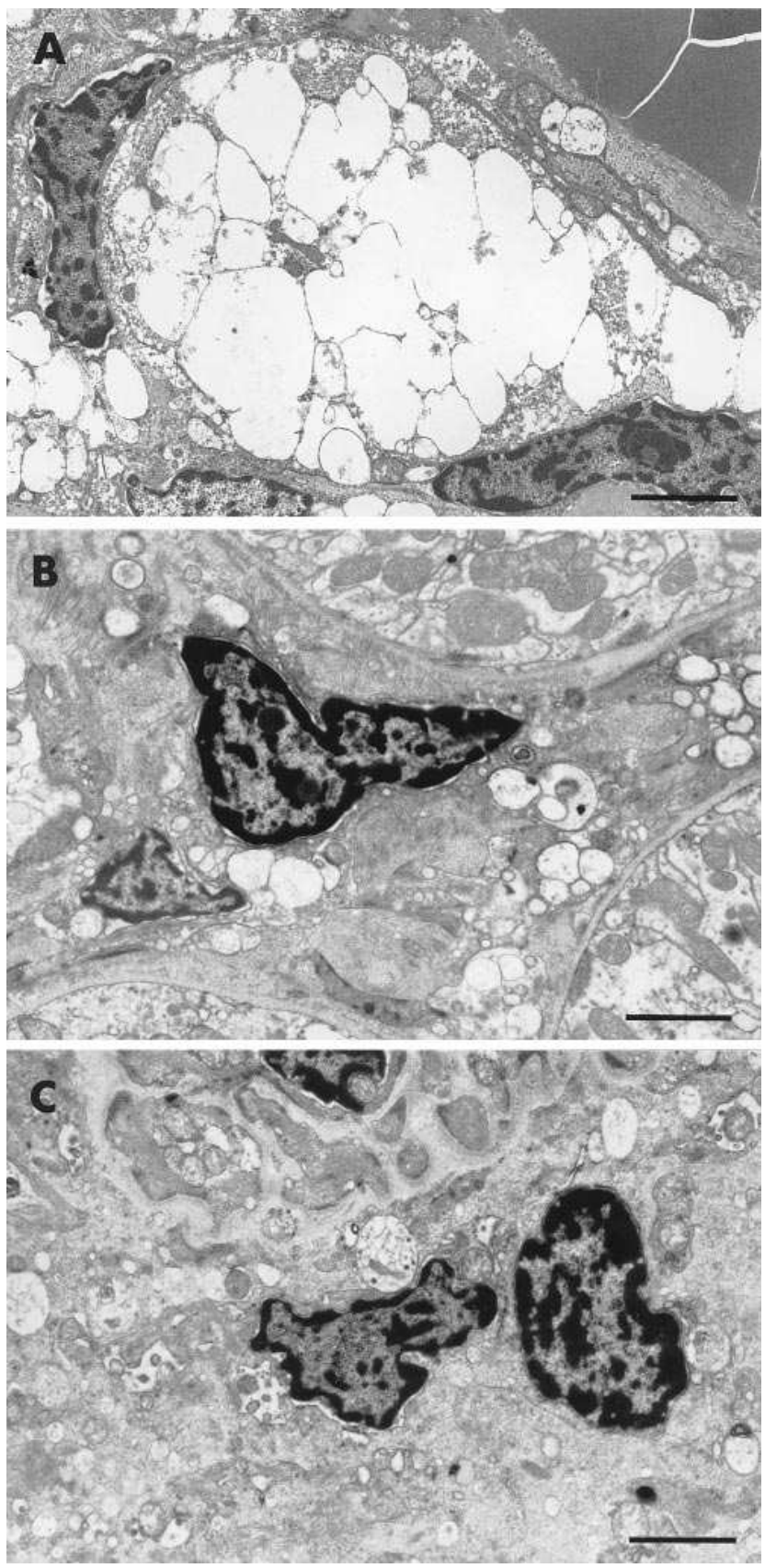

Figure 7. Electron microscopy of renal interstitial fibroblasts in $(A)$ a 6-mo-old untreated control MPS VI cat with extensive lysosomal vacuolation, $(B)$ reduced numbers of storage vacuoles in cat $\mathrm{A},(C)$ almost complete normalization in cat $\mathrm{C}$. The renal interstitium of the treated cats showed a dramatic reduction in the amount of vacuolation in fibroblasts (cat B, data not shown) and the basement membranes showed no evidence of immune complex deposition. Bar, $2 \mu \mathrm{m}$.

and for the duration of ERT in cat C. Similar tissue half-lives have been reported for bovine testes acid $\alpha$-glucosidase in mice (35) and for recombinant $\beta$-D-glucuronidase in MPS VII mice (13).

Therapy was instituted in cats A and B after skeletal pathology was well established. Our studies show that at the dose rates used, long term therapy was unable to significantly alter
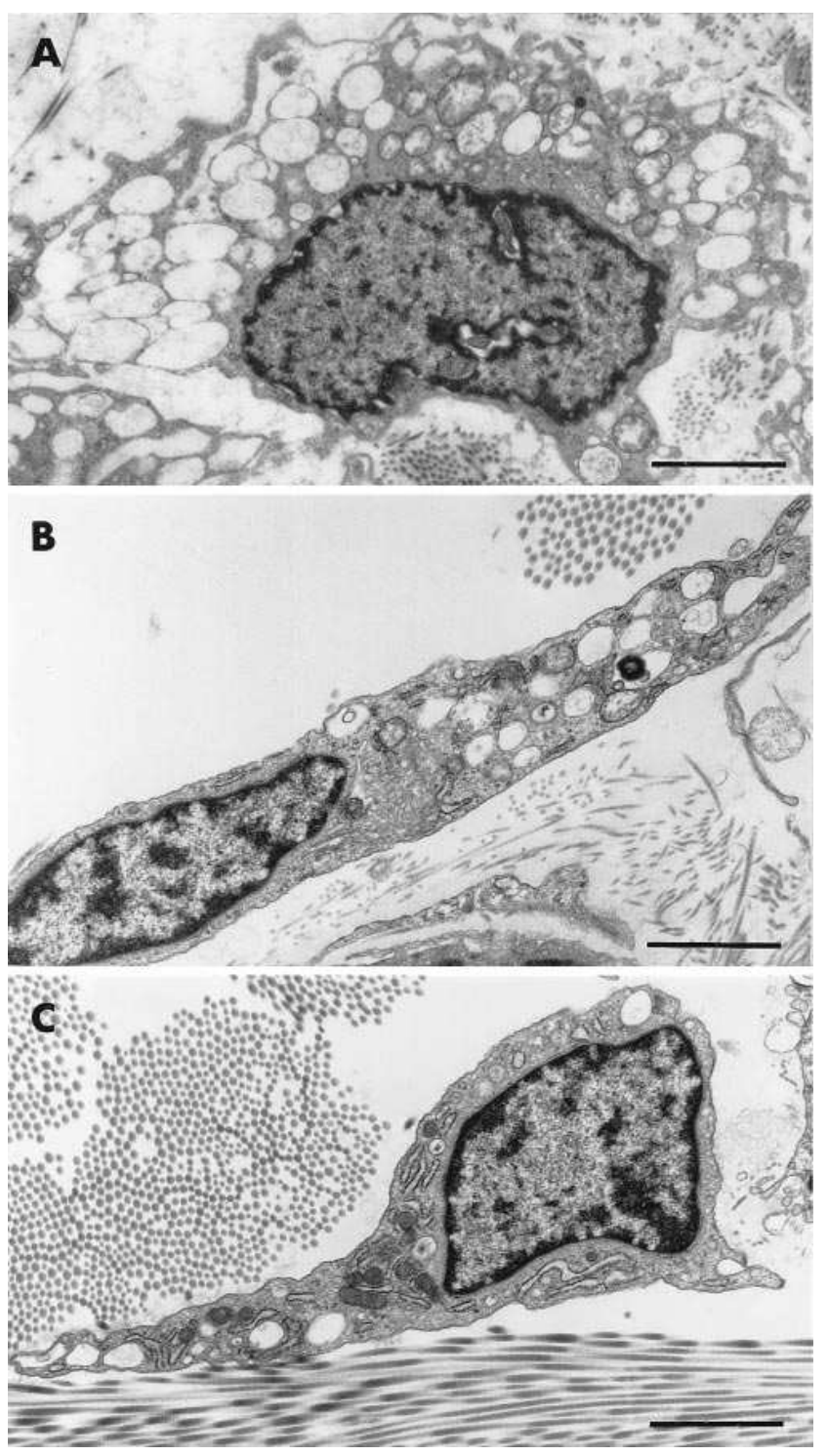

Figure 8. Electron microscopy of fibroblasts from skin biopsies in $(A)$ cat A, 2 mo after onset of therapy with numerous enlarged lysosomes, $(B$ and $C$ ) cat A, 5 mo after onset of therapy with greatly reduced degree of lysosomal vacuolation. Skin in cat $\mathrm{C}$ showed marked clearing of lysosomal storage in fibroblasts to almost normal levels, compared with the untreated MPS VI control (data not shown). Cats A and B also showed reduction in the degree of fibroblast vacuolation in postmortem skin samples compared to skin biopsies taken around the time of onset of ERT (data not shown). Bar, $2 \mu \mathrm{m}$.

the radiographic appearance of skeletal disease in these cats. Progression of disease in cat $\mathrm{C}$ was clinically indistinguishable from cats $\mathrm{A}$ and $\mathrm{B}$, despite much earlier onset of therapy at 2 mo of age. This may reflect the different dose frequency (fortnightly), or perhaps the clinical heterogeneity in MPS VI cats observed within our colony and other colonies (26). However, using bone morphometry as a more objective measure, increased bone volume appeared to correlate with earlier onset of therapy, with the highest value found in cat $\mathrm{C}$ (onset ERT at $2 \mathrm{mo}$ ) followed by cat A (onset $7 \mathrm{mo}$ ) although values still fell well below that of the normal control cat. ERT was unable to improve bone volume once skeletal maturity was 


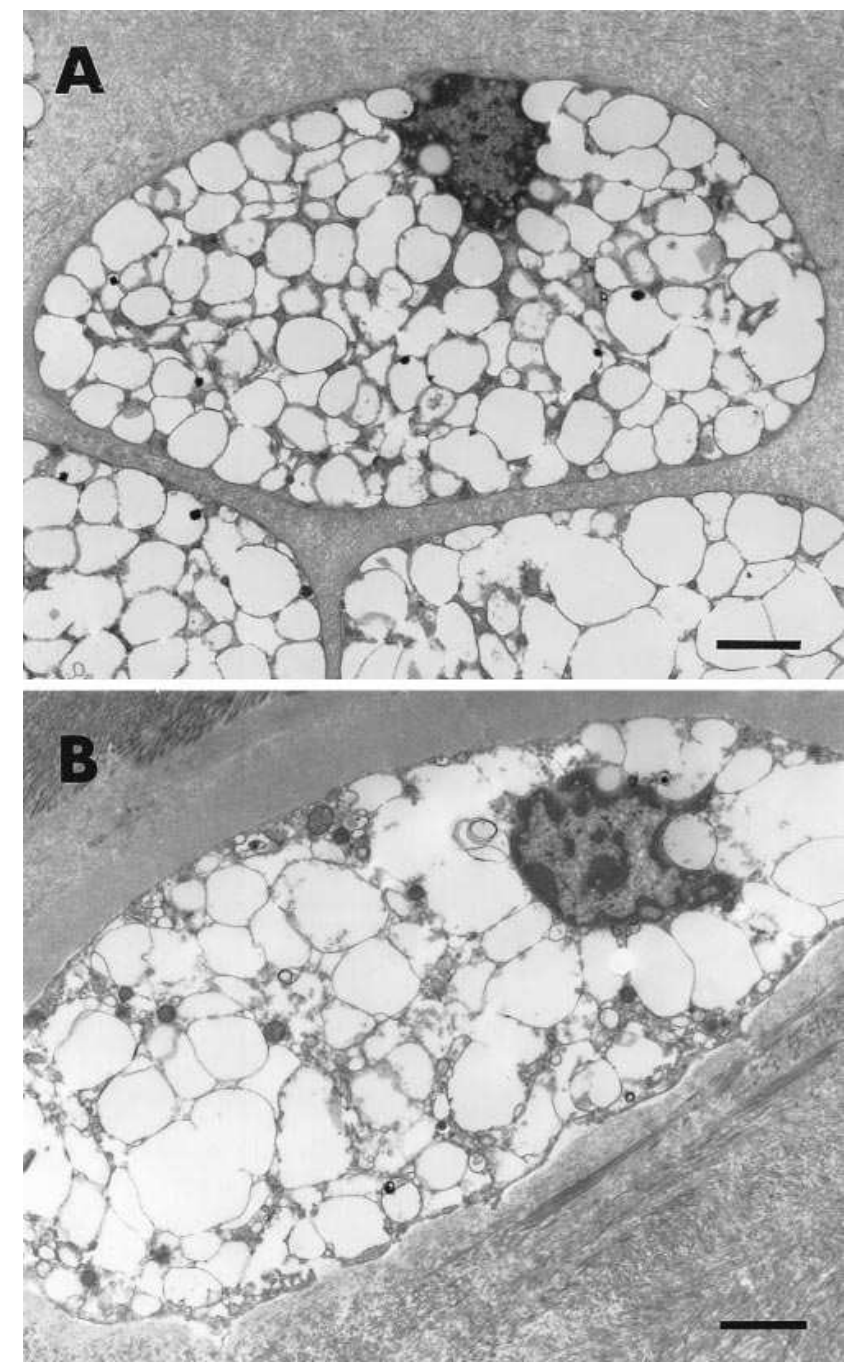

Figure 9. Electron microscopy of chondrocytes in $(A)$ cat A, from an iliac crest biopsy 2 mo after onset of therapy showing numerous large empty lysosomal vacuoles, $(B)$ cat $\mathrm{A}$, in tracheal cartilage 20 mo after onset of therapy showing no reduction in degree of vacuolation. Bar, $2 \mu \mathrm{m}$. Chondrocytes from articular and tracheal cartilage from cats $\mathrm{A}, \mathrm{B}$ and $\mathrm{C}$ were distended with numerous membrane bound inclusions and were indistinguishable from an untreated MPS VI cat.

reached, as seen in cat B. A study investigating earlier onset of therapy at increased dose and dose frequency is currently in progress (unpublished).

The increased bone volume seen in the earliest treated cat, cat $\mathrm{C}$, may be due to improved enzyme availability to the growth plate whilst undergoing rapid growth. The increased trabecular number also seen in this cat conflicts with results seen in bone marrow transplanted MPS VI cats where trabecular number appeared unchanged (38). Obviously this result needs to be evaluated in more animals undergoing ERT. MPS VII mice given multiple injections of $\beta$-D-glucuronidase improved in bone length but were not normalized and no morphometric data was reported (14). However, there may be important differences in growth plate regulation between animals such as rats and mice, with open growth plates throughout life, and those such as cats, dogs and humans, that show growth plate closure on maturity. Therefore studies of skeletal pathology in the MPS and their response to therapy may be more appropriate in larger animal models with similar growth regulation to humans.

Improved mobility has been reported in patients following bone marrow transplantation (39). The subjective improvement in mobility in one cat after onset of ERT, and after increased dose and frequency of dosing, may have been as a result of a reduction in joint capsule storage, however, fluctuations in the use of hindlimbs in the same cat prior to ERT and dose changes remain unexplained. Localization of spinal cord compression at postmortem to the lower cervical/upper thoracic region in cat $\mathrm{C}$ differs from another report where MPS VI cats had cord compression in the thoracolumbar region (25). We have since observed spinal cord compression in the cervicothoracic region of the majority of untreated MPS VI cats as well as in the thoracolumbar region of some of these cats (unpublished observations).

All cats tolerated enzyme administration with minimal side effects, indicating the potential viability of long term ERT at least in the feline model for MPS VI. It was not possible to correlate development of antibody titer and subsequent fluctuations with clinical well-being of the cats in this study. The dramatic reduction in antibody titer in cat A after enzyme administration indicates antibody binding to the rh4S enzyme. This antibody may have diminished the effectiveness of the rh4S therapy in this cat as plasma antibody from the same cat was able to inhibit rh4S activity in vitro. The rh4S/antibody complex may also alter the availability and subsequent efficacy of rh4S in the lysosomal compartment $(40,41)$. Analysis of rh4S activity in tissues taken $7 \mathrm{~d}$ after enzyme infusion in cats $\mathrm{A}$ and $\mathrm{B}$ showed that cat B had detectable rh4S in most tissues, whereas cat A only had activity detectable in liver (data not shown). This supports the hypothesis of reduced efficacy of rh4S in the presence of high titer antibody as seen in cat A. In future studies we will examine the intracellular fate of antibody bound rh4S and use $44 \mathrm{~S}$ to evaluate any differences in antibody production and efficacy in MPS VI cats. The observed natural titers of non-immune cats to rh4S is significant but not unprecedented $(42,43,44)$ and is also under further investigation.

In conclusion, our results show that there was response to long term ERT histologically in liver, kidney and skin fibroblasts. There was no obvious reversal of skeletal changes radiographically, however there was a trend towards normalization of bone mineral volume in vertebral bone samples, correlating with earlier onset of therapy. More extensive evaluation is needed in larger numbers of animals using increased dose rates and frequency, with onset of treatment as soon as possible after birth. The effect of antibody titer on efficacy of therapy should be evaluated, and methods to improve penetration of enzyme to cartilage and cornea also need to be developed.

\section{Acknowledgments}

We appreciate and acknowledge the encouragement, technical support, and original cats heterozygous for MPS VI (NIH DK-25759), given by Professor Mark Haskins from the University of Pennsylvania. The authors gratefully acknowledge animal care staff at the Institute of Medical and Veterinary Science for the daily care of the cat colony, Dr. Michael Hammerton for slit lamp examinations of the 
cats, and Dr. Tim Kuchel for initial input in distribution studies. We also thank Mr. Peter $\mathrm{M}^{\mathrm{c}}$ Neil (IMVS) for technical assistance in the preparation of undecalcified bone sections, Mr. Alvis Jaunzems, Mr. Richard Davey and staff at the WCH Electron Microscopy Unit for assistance with electron microscopy and Mr. Richard Davey for preparation of photographic artwork, Dr. Tony Bourne for assistance with histology, Mr. Michael Brogan and Dr. Peter Clements for purification of enzyme used in the distribution studies, and Ms. Jill Durrant for enzyme dephosphorylation studies. We would also like to thank CSL Limited for the provision of media containing rh4S.

This work was supported by the WCH Foundation, Channel 7 Children's Research Foundation, CSL Limited and the National Health and Medical Research Council of Australia.

\section{References}

1. Neufeld, E.F., and J. Muenzer. 1995. The mucopolysaccharidoses. In The Metabolic and Molecular Basis of Inherited Disease. ed. 7. C.R. Scriver, A.L. Beaudet, W.S. Sly, and D. Valle, editors. McGraw-Hill, New York. 2465-2494.

2. Hopwood, J.J., and C.P. Morris. 1990. The mucopolysaccharidoses: diagnosis, molecular genetics and treatment. Mol. Biol. Med. 7:381-404.

3. van de Kamp, J.J.P., M.F. Niermeijer, K. von Figura, and M.A.H. Giesberts. 1981. Genetic heterogeneity and clinical variability in the Sanfilippo syndrome (types A, B, and C). Clin. Genet. 20:152-160.

4. Maroteaux, P., and M. Lamy. 1965. Hurler's disease, Morquio's disease, and related mucopolysaccharidoses. J. Pediatr. 67:312-323.

5. Hopwood, J.J., A. Vellodi, H.S. Scott, C.P. Morris, T. Litjens, P.R. Clements, D.A. Brooks, A. Cooper, and J.E. Wraith. 1993. Long-term clinical progress in bone marrow transplanted mucopolysaccharidosis type I patients with a defined genotype. J. Inher. Metab. Dis. 16:1024-1033.

6. Field, R.E., J.A.F. Buchanan, M.G.J. Copplemans, and P.M. Aichroth. 1994. Bone-marrow transplantation in Hurler's syndrome-effect on skeletal development. J. Bone Joint Surg. Br. 76-B:975-981.

7. Brady, R.O., J.A. Barranger, P.G. Pentchev, F.S. Furbish, and A.E. Gal. 1982. Prospects for enzyme replacement therapy in heritable metabolic disorders. In Inborn Errors Of Metabolism in Humans. F. Cockburn and R. Gitzelmann, editors. MTP Press Ltd, Lancaster, England. 139-154.

8. Furbish, F.S., C.J. Steer, N.L. Krett, and J.A. Barranger. 1981. Uptake and distribution of placental glucocerebrosidase in rat hepatic cells and effects of sequential deglycosylation. Biochim. Biophys. Acta. 673:425-434

9. Barton, N.W., F.S. Furbish, G.J. Murray, M. Garfield, and R.O. Brady. 1990. Therapeutic response to intravenous infusions of glucocerebrosidase in a patient with Gaucher disease. Proc. Natl. Acad. Sci. USA. 87:1913-1916.

10. Jezyk, P.F., M.E. Haskins, D.F. Patterson, W.J. Mellman, and M. Greenstein. 1977. Mucopolysaccharidosis in a cat with arylsulfatase B deficiency: a model of Maroteaux-Lamy syndrome. Science (Wash. DC). 198:834836.

11. Haskins, M.E., G.D. Aguirre, P.F. Jezyk, and D.F. Patterson. 1980. The pathology of the feline model of mucopolysaccharidosis VI. Am. J. Pathol. 101: 657-674.

12. Yoshida, M., J. Noguchi, H. Ikadai, M. Takahashi, and S. Nagase. 1993. Arylsulfatase B deficient mucopolysaccharidosis in rats. J. Clin. Invest. 91:10991104.

13. Vogler, C., M. Sands, A. Higgins, B. Levy, J. Grubb, E.H. Birkenmeier, and W.S. Sly. 1993. Enzyme replacement with recombinant $\beta$-glucuronidase in the newborn mucopolysaccharidosis type VII Mouse. Pediatr. Res. 34:837-840.

14. Sands, M.S., C. Vogler, J.W. Kyle, J.H. Grubb, B. Levy, N. Galvin, W.S. Sly, and E.H. Birkenmeier. 1994. Enzyme replacement therapy for murine mucopolysaccharidosis type VII. J. Clin. Invest. 93:2324-2331.

15. Birkenmeier, E.H., J.E. Barker, C.A. Vogler, J.W. Kyle, W.S. Sly, B. Gwynn, B. Levy, and C. Pegors. 1991. Increased life span and correction of metabolic defects in murine mucopolysaccharidosis type VII after syngenic bone marrow transplantation. Blood. 78:3081-3092.

16. Shull, R.M., E.D. Kakkis, M.F. McEntee, S.A. Kania, A.J. Jonas, and E.F. Neufeld. 1994. Enzyme replacement in a canine model of Hurler syndrome. Proc. Natl. Acad. Sci. USA. 91:12937-12941.

17. McGovern, M.M., D.T. Vine, M.E. Haskins, and R.J. Desnick. 1982. Purification and properties of feline and human arylsulfatase B isozymes. J. Biol. Chem. 257:12605-12610.

18. Gibson, G.J., G.T.P. Saccone, D.A. Brooks, P.R. Clements, and J.J. Hopwood. 1987. Human $N$-acetylgalactosamine-4-sulphate sulphatase. Biochem. J. 248:755-764.

19. Peters, C., B. Schmidt, W. Rommerskirch, K. Rupp, M. Zuhlsdorf, M. Vingron, H.E. Meyer, R. Pohlmann, and K. von Figura. 1990. Phylogenetic conservation of arysulphatases: cDNA cloning and expression of human arylsulphatase. J. Biol. Chem. 265:3374-3381.
20. Schuchman, E.H., C.E. Jackson, and R.J. Desnick. 1990. Human arylsulfatase B: MOPAC cloning, nucleotide sequence of a full length cDNA, and regions of amino acid identity with arylsulfatases A \& C. Genomics. 6:149-158.

21. Anson, D.S., J.A. Taylor, J. Bielicki, G.S. Harper, C. Peters, G.J. Gibson, and J.J. Hopwood. 1992. Correction of human mucopolysaccharidosis type VI fibroblasts with recombinant $\mathrm{N}$-acetylgalactosamine-4-sulphatase. Biochem. J. 284:789-794.

22. Stanley, P., V. Caillibot, and L. Siminovitch. 1975. Selection and characterization of eight phenotypically distinct lines of lectin-resistant Chinese Hamster ovary cells. Cell. 6:121-128.

23. Bielicki, J., J.J. Hopwood, P.J. Wilson, and D.S. Anson. 1993. Recombinant human iduronate-2-sulphatase: correction of mucopolysaccharidosis type II fibroblasts and characterization of the purified enzyme. Biochem. J. 289:241246.

24. Brooks, D.A., G.J. Gibson, and J.J. Hopwood. 1994. Immunochemical characterization of feline and human $\mathrm{N}$-acetylgalactosamine 4-sulfatase. Biochem. Med. Metab. Biol. 53:58-66.

25. Haskins, M.E., S.A. Bingel, J.W. Northington, C.D. Newton, R.D Sande, P.F. Jezyk, and D.F. Patterson. 1983. Spinal cord compression and hindlimb paresis in cats with mucopolysaccharidosis VI. J. Am. Vet. Med. Assoc. 182:983-985.

26. Konde, L.J., M.A. Thrall, P. Gasper, S.M. Dial, K. McBiles, S. Colgan, and M. Haskins. 1987. Radiographically visualized skeletal changes associated with mucopolysaccharidosis VI in cats. Vet. Radiol. 28:223-228.

27. Gold, E. 1979. A simple spectrophotometric method for estimating glycosaminoglycan concentrations. Anal. Biochem. 99:183-188.

28. Hopwood, J.J., and J.R. Harrison. 1982. High-resolution electrophoresis of urinary glycosaminoglycans: an improved screening test for the mucopolysaccharidoses. Anal. Biochem. 119:120-127.

29. Brooks, D.A., P.A.G. McCourt, G.J. Gibson, and J.J. Hopwood. 1990. Immunoquantification of the low abundance lysosomal enzyme $N$-acetylgalactosamine 4-sulfatase. J. Inherited Metab. Dis. 13:108-120.

30. Recker, R.R. 1983. Bone Histomorphometry: Techniques and Interpretation. CRC Press, Inc., Florida.

31. Kampine, J.P., R.O. Brady, J.N. Kanfer, M. Feld, and D. Shapiro. 1966. Diagnosis of Gaucher's disease and Niemann-Pick disease with small samples of venous blood. Science (Wash. DC). 155:86-88.

32. Rattazzi, M.C., A.M. Appel, H.J. Baker, and J. Nester. 1981. Toward enzyme replacement in $\mathrm{GM}_{2}$ gangliosidosis: inhibition of hepatic uptake and induction of CNS uptake of human $\beta$-hexosaminidase in the cat. In Lysosomes and Lysosomal Storage Diseases. J.W. Callahan and J.A. Lowden, editors. Raven Press, New York. 405-424.

33. von Figura, K., and A. Hasilik. 1986. Lysosomal enzymes and their receptors. Annu. Rev. Biochem. 55:167-193.

34. Bou-Gharios, G., D. Abraham, and I. Olsen. 1993. Lysosomal storage diseases: mechanisms of enzyme replacement therapy. Histochem. J. 25:593605 .

35. Van der Ploeg, A.T., M.A. Kroos, R. Willemsen, N.H.C. Brons, and A.J.J. Reuser. 1991. Intravenous administration of phosphorylated acid $\alpha$-glucosidase leads to uptake of enzyme in heart and skeletal muscle of mice. J. Clin. Invest. 87:513-518.

36. Navarro, C., C. Dominguez, M. Costa, and J.J. Ortega. 1991. Bone marrow transplant in a case of mucopolysaccharidosis I Scheie phenotype: skin ultrastructure before and after transplantation. Acta. Neuropathol. 82:33-38.

37. Taylor, J.A., G.J. Gibson, D.A. Brooks, and J.J. Hopwood. 1990. Human $\mathrm{N}$-acetylgalactosamine-4-sulphatase biosynthesis and maturation in normal, Maroteaux-Lamy and multiple-sulphatase-deficient fibroblasts. Biochem. J. 268:379-386.

38. Norridin, R.W., K.S. Moffat, M.A. Thrall, and P.W. Gasper. 1993. Characterisation of osteopenia in feline mucopolysaccharidosis VI and evaluation of bone marrow transplantation therapy. Bone. 14:361-367.

39. McGovern, M.M., M.D. Ludman, M.P. Short, L. Steinfeld, M. Kattan, E.L. Raab, W. Krivit, and R.J. Desnick. 1986. Bone marrow transplantation in Maroteaux-Lamy syndrome (MPS type 6): Status 40 months after BMT. In Bone Marrow Transplantation for Treatment of Lysosomal Storage Diseases. W. Krivit, and N. Paul, editors. March of Dimes, Birth Defects. 22:41-53.

40. Amigorena, S., J. Drake, P. Webster, and I. Mellman. 1994. Transient accumulation of new class II MHC molecules in a novel endocytic compartment in B lymphocytes. Nature (Lond.). 369:113-120.

41. Tulp, A., D. Verwoerd, B. Dobberstein, H. Ploegh, and J. Pieters. 1994. Isolation and characterization of the intracellular MHC class II compartment. Nature (Lond.). 369:120-126.

42. Cox, K.O., D. Evans, D.A. Brooks, and D.A. Cunliffe. 1979. In vitro investigation of autoantibody-secreting peritoneal cells and their regulation. Immunology. 38:355-365.

43. Zoller, M., and M. Achtnich. 1991. Evidence for regulation of naturally activated autoreactive B cells. Eur. J. Immunol. 21:305-312.

44. Underwood, J.R., X.F. Csar, B.A. Veitch, and M.T. Hearn. 1993. Characterization of the specificity of a naturally occurring monoclonal anti-thymocyte autoantibody derived from an unimmunized, neonatal Balb/c mouse. Thymus. 21:199-219. 